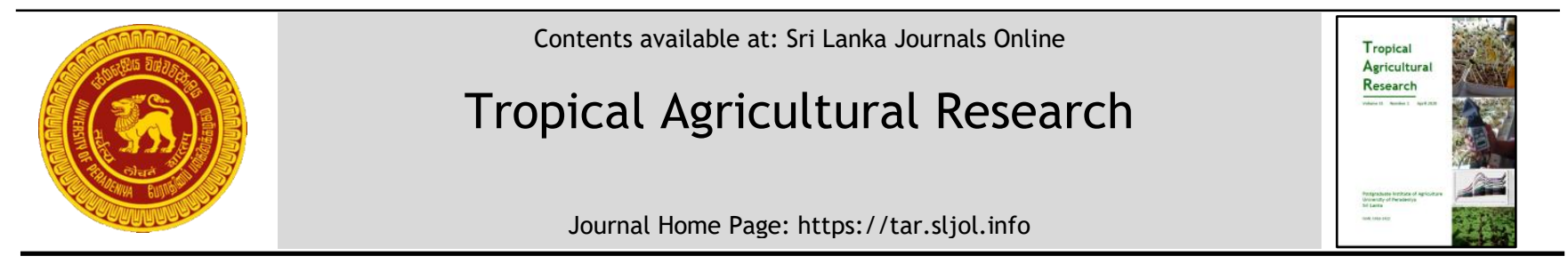

\title{
Assessment of Marker Based Genotype Diversity of Saltol QTL in Relation to Seedling Stage Salinity Tolerance in Selected Rice Genotypes
}

\author{
Y.A.P.K. Dayasena ${ }^{1 *}$, U.A.K. Udawela ${ }^{2}$ and S.D.S.S. Sooriyapathirana ${ }^{3}$ \\ 1 Postgraduate Institute of Science, University of Peradeniya, Sri Lanka. \\ ${ }^{2}$ Rice Research and Development Institute, Bathalagoda, Sri Lanka. \\ ${ }^{3}$ Department of Molecular Biology and Biotechnology, Faculty of Science, University of Peradeniya, Sri Lanka
}

\section{ARTICLE INFO}

\section{Article history:}

Received: 24 July 2019

Accepted: 07 November 2019

Available online: 1 April 2020

\section{Keywords:}

Marker Assisted Selection

Pokkali

Polymorphism Information Content,

Saltol QTL

SSR markers

\section{Citation:}

Dayasena, Y.A.P.K., Udawela, U.A.K. and

Sooriyapathirana, S.D.S.S. (2020).

Assessment of Marker Based Genotype

Diversity of Saltol QTL in Relation to

Seedling Stage Salinity Tolerance in

Selected Rice Genotypes. Tropical

Agricultural Research, 31(2): 01-11.

DOI: http://doi.org/10.4038/tar.v31i2.8362

Dayasena, Y.A.P.K. (iD

https://orcid.org/0000-0002-7264-824X

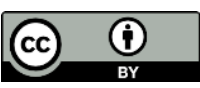

\section{ABSTRACT}

Salinity stress is one of the major soil problems in relation to rice production in Sri Lanka. Development of salinity tolerant rice through rice breeding is a key solution for salinity problem. Saltol is the major Quantitative Trait Loci (QTL) responsible for salt tolerance at the seedling stage of the rice plants which is mapped on chromosome one of the rice genome. To select most salt tolerant rice genotypes for future breeding programmes and test the usefulness of the Microsatellite (SSR) markers associated with Saltol QTL, 18 rice varieties were screened using electrical conductivity 12 $\mathrm{dSm}^{-1}$ nutrient solution for salt tolerance at the seedling stage using a visual score of 1-9 scale. Six polymorphic SSR markers linked to the Saltol QTL were used to determine the impact of these markers associated with salt tolerance in rice. Results of the phenotypic screening of 18 rice genotypes showed different responses for salt stress at the seedling stage. Based on the phenotypic screening rice genotypes were categorized into four groups, and Pokkali accessions were the most tolerant genotypes for salinity stress which can be useful as donor parents for future rice breeding programs. Microsatellite marker RM10843 showed highest allelic number while RM140 and RM10748 showed lowest allelic number. Polymorphism information content (PIC) value varied from 0.1780 for RM10748 to 0.7659 for marker alleles. Based on the six SSR markers, 18 rice genotypes were clustered into two groups and salinity tolerant Pokkali accessions were grouped in a separate cluster. Salinity tolerant and susceptible genotypes were clearly discriminated by RM10852 marker in 3\% agarose gel and positively associated with the result of the phenotypic screening. Therefore, the marker will be useful in Marker Assisted Selection (MAS) in rice breeding programmes for salinity tolerance. 


\section{INTRODUCTION}

Rice is one of the most important cereal crops which serves as the staple food for one-third of the global population. It is the world's third-largest cereal crop after wheat and maize (Mohommad-Nejad et al., 2010). However, many abiotic stresses such as salinity, iron toxicity, acidity and drought greatly affect the rice production in these regions. At present, salinity is the second most widespread abiotic problem next to drought (Islam et al., 2010). Around 21.5 million hectares of the land area is seriously affected by salinity in the south and southeast Asian region alone, where majority of the rice-growing areas of the world are situated (Li et al., 2014). Salinity is a major constraint to expanding rice cultivation in Sri Lanka. Nearly $70 \%$ of the coastal rice lands are reported to be affected by salinity (De Costa et al., 2012). Sirisena and Herath (2009) stated that salinity is gradually spreading in rice lands of Sri Lanka both in coastal and inland regions. Out of 12,000 ha of cultivated rice lands in Jaffna, about 3,000 ha are unproductive due to salinity (Rajadurai, 2003).

Rice plant is highly sensitive for salt stress, especially at early seedling and late reproduction stages (Zeng and Shannon, 2000), where salinity greatly affects rice yield. Vinod et al. (2013) reported a 12\% yield reduction for every unit of $\mathrm{dSm}^{-1}$ of electrical conductivity (EC) above the threshold level of tolerance of $3.0 \mathrm{dSm}^{-1}$.

Breeding a salinity tolerant rice variety is one of the best approaches to overcome the effect of adverse saline soil condition. The rapid advancement of DNA based molecular marker technologies and their applications in plant breeding programmes were reported in the last two decades. Unravelling of rice genome has given an infinite opportunity to produce SSR markers throughout the rice genome (Thomson et al., 2010). Therefore, a higher number of SSR markers are developed which are tightly linked to the important genes and QTLs regulating different important mechanisms in rice plant. Saltol is one of the major QTLS for salt tolerance at the seedling stage
(Bonilla et al., 2002). Recently the Saltol QTL has been mapped by several studies (Bonilla et al., 2002; Thomson et al., 2010; Soda et al., 2013). One of the studies reported that Saltol QTL is located between the SSR marker RM1287 and RM6711 (10.8Mb -16.4Mb) in the short arm of the rice chromosome one (Thomson et al., 2010).

Platten et al. (2006) reported SKC1 (later named as gene OsHKT1;5) is a causal gene underlying the Saltol QTL which is supported to control sodium/potassium $\left(\mathrm{Na}^{+} / \mathrm{K}^{+}\right)$ratio. SKC1 was found to encode a sodium transporter protein that helps control $\mathrm{Na}^{+} / \mathrm{K}^{+}$homeostasis through the unloading of sodium from the xylem, which has been functioning mainly in roots to reduce the amount of $\mathrm{Na}^{+}$ions that are transported to the leaves (Ren et al., 2005). There are many functional SSR markers which are tightly linked to the important loci of the Saltol QTL. Therefore, those markers will be very useful in genetic studies of the Saltol region and will provide significant assistance for future salinity tolerance rice breeding programmes. The objectives of the present study were as follows: The assessment of salinity tolerant ability of the popular local rice varieties and group those varieties based on their salinity tolerance level at the seedling stage, select the useful donor parents for future salinity tolerant rice breeding programmes, identification of positively associated SSR marker/markers for salinity tolerance with the results of phenotype screening for salinity tolerance, and identification of useful SSR markers for marker assisted selection to assist future salinity tolerant rice breeding programmes.

\section{MATERIALS AND METHODS}

The laboratory work was conducted at the Rice Research and Development Institute (RRDI) at Bathalagoda from May 2016 to November 2017. Sixteen rice varieties and two Pokkali accessions were used for the study. Seeds of each variety were obtained from RRDI, Bathalagoda and Plant Genetic Resource Center, Gannoruwa, Sri Lanka. 


\section{Morphological screening}

The salinity tolerant ability at the seedling stage of the 16 rice varieties namely $\mathrm{Bg} 369$, Bg359, IR42, IR46, Bg250, Bg300, Bg360, Bg358, Bg370, Bg357, Bg310, Bg94/1, IR36, Bg380, At303, At362 and two Pokkali accessions were tested by using the method developed by Gregorio et al. (1997b) with some modifications. Varieties were selected based on different criteria such as reported salinity tolerant ability under field conditions, popularity of the variety and usability of each variety for future breeding programmes as donor and recipient parents. Pokkali IRRI accession, which is the most salinity tolerant IRRI accession and, Pokkali local accession 5557, which is one of the most salinity tolerant local accessions (Senanayake et al., 2017a) were used as known salinity tolerant genotypes.

The morphological screening was done in the green house of the RRDI, Bathalagoda. Two replicates (two trays) were used for each variety in Complete Randomized Design (CRD) for the experiment. Each variety was separately planted in the each replicate with twenty-five seedlings. Rectangular Styrofoam sheets of $50 \mathrm{~cm}$ (Length, L) x $30 \mathrm{~cm}$ (Width, W) x $1.25 \mathrm{~cm}$ (Depth, D) were used for anchoring seedlings on the nutrition solution. Holes of $1 \mathrm{~cm}$ diameter were drilled, which were spaced $2.5 \mathrm{~cm}$ within the rows and $4 \mathrm{~cm}$ between the rows. A nylon net with sieve size less than $1 \mathrm{~mm}$ was fixed on one side of each styrofoam board. Plastic trays of $55 \mathrm{~cm}$ (L) $\times 35 \mathrm{~cm} \mathrm{(W)} \times 8 \mathrm{~cm}$ (D) were used to fill the nutrient solution and the prepared styrofoam board floated on these trays without letting them move.

\section{Seed germination and maintenance during the first twelve days}

Sterilized seeds were placed in petri dishes on moistened filter paper and incubated for 48 hours to facilitate germination as in Gregorio et al. (1997b). Two pre-germinated seeds were inserted per each hole on the styrofoam seedling float and radicle was carefully inserted through nylon mesh.
Pre-germinated seeds were maintained under the water for three days to recover the damage of roots. After three days, the water was replaced by $2 \mathrm{dSm}^{-1}$ Albert solution at $\mathrm{pH}$ 6.5. The seedlings were maintained for nine days in these conditions. One well grown seedling was retained while removing the poorly grown seedling in each hole. Twenty-five healthy seedlings were remained in each replicate. Freshly prepared Albert solution at the $2 \mathrm{dSm}^{-1}$ was added to maintain the constant level of the nutrient solution to avoid plants getting dried in first 12 days.

\section{Initiating salt stress condition and evaluation of the seedlings}

Pre-washed table salt was used to prepare a solution with electrical conductivity (EC) 10 $\mathrm{dSm}^{-1}$. Albert nutrient solution was added to the salt solution to increase the EC up to12 $\mathrm{dSm}^{-1}$ and $\mathrm{pH}$ was adjusted to 6.5 using $1 \mathrm{M}$ sodium hydroxide solution. This solution was used as the stress solution to evaluate the response of the rice seedlings. The initial nutrient solution $\left(2 \mathrm{dSm}^{-1}\right)$ was replaced by using $12 \mathrm{dSm}^{-1}$ stress solutions to start the salt stress on rice seedlings, when seedlings were 12 days old. The rice seedlings were exposed for the salt stress condition for 14 days. The control experiment (unstressed seedlings) consisted of 10 plants of each variety which was maintained with Albert solution at $2 \mathrm{dSm}^{-1}$ EC and $\mathrm{pH} 6.5$ simultaneously. The EC and $\mathrm{pH}$ of the stress solution were checked every 3 days and kept constant throughout the stress period by adding freshly prepared $12 \mathrm{dSm}^{-1}$ solution as same to the initial stress solution.

The seedlings were visually inspected for salt stress symptoms at 7, 10 and 14 days after imposing the stress solution. Salt stress symptoms in each plot were inspected separately and tolerance score was assigned based on modified standard evaluating score system (Table 1) developed by Gregorio et al. (1997b). Finally average tolerance score was given for each variety and categorized as in Table 1. To check the differences of response among varieties for salinity 
tolerance at seedling stage, ANOVA was performed using General Linear Model (GLM) procedure followed by the Duncan
Multiple Range Test (DMRT). The evaluated results were used for the molecular markerbased genotype diversity analysis.

Table 1: Modified standard evaluating score system for salinity screening at the seedling stage

\begin{tabular}{lll}
\hline $\begin{array}{l}\text { Tolerance } \\
\text { Score }\end{array}$ & \multicolumn{1}{c}{ Observation } & \multicolumn{1}{c}{ Tolerance } \\
\hline $\mathbf{1}$ & Normal growth, no leaf symptoms & Highly tolerant (HT) \\
$\mathbf{3}$ & $\begin{array}{l}\text { Nearly normal growth, but leaf tips of few leaves } \\
\text { whitish and rolled }\end{array}$ & Tolerant (T) \\
$\mathbf{5}$ & $\begin{array}{l}\text { Growth severely retarded; most leaves rolled; only a } \\
\text { few are elongating }\end{array}$ & $\begin{array}{l}\text { Moderately tolerant } \\
\text { (MT) }\end{array}$ \\
$\mathbf{7}$ & $\begin{array}{l}\text { Complete cessation of growth; most leaves dry; some } \\
\text { plants drying }\end{array}$ & $\begin{array}{l}\text { Susceptible (S) } \\
\mathbf{9}\end{array}$ \\
\hline
\end{tabular}

Source: Gregorio et al. (1997b)

\section{SSR marker based analysis}

Six polymorphic SSR markers: RM10852, RM10843, RM140, RM10748, RM3412, and RM8094 which are located in the Saltol QTL region were used to study the genetic diversity in the Saltol QTL in selected rice genotypes. These 6 markers were tightly linked to Saltol QTL and which are spanning from $11.2 \mathrm{Mbp}$ to $14.2 \mathrm{Mbp}$ in the Saltol region of the chromosome one of the rice genome (Thomson et al., 2010).

The total genomic DNA in 18 rice genotypes was extracted by using CTAB DNA extraction method. Polymerase Chain Reaction (PCR) was performed by using My cycler" Thermal cycler (BIORAD, 2800 Woods, Madison, USA). The PCR amplification was done with Promega green PCR master mixture (PCR master mixture system, USA), with a total volume $15 \mu \mathrm{L}$, which contained $6 \mu \mathrm{L}$ of the master mixture, $4 \mu \mathrm{L}$ of nuclease-free water, $1 \mu \mathrm{L}$ of the forward primer, $1 \mu \mathrm{L}$ of reverse prime and $3 \mu \mathrm{L}$ of Genomic DNA. PCR was conducted with an initial denaturation step at $94{ }^{\circ} \mathrm{C}$ for $5 \mathrm{~min}$ followed by 35 thermal cycles of denaturation at $94{ }^{\circ} \mathrm{C}$ for $1 \mathrm{~min}$, annealing temperature $56^{\circ} \mathrm{C}, 63^{\circ} \mathrm{C}, 65^{\circ} \mathrm{C}, 58$ ${ }^{\circ} \mathrm{C}, 57^{\circ} \mathrm{C}, 52{ }^{\circ} \mathrm{C}$ were respectively used for
RM10852, RM10843, RM140, RM10748, RM3412, and RM8094 primers for $1 \mathrm{~min}$, extension at $72{ }^{\circ} \mathrm{C}$ for $1 \mathrm{~min}$, terminated with a final extension of $5 \mathrm{~min}$ at $72{ }^{\circ} \mathrm{C}$. The PCR products were resolved with $3 \%$ agarose gel electrophoresis for 2.5 hours and gels were stained by adding $10 \mu \mathrm{L}$ of $10 \mathrm{mg} / \mu \mathrm{L}$ ethidium bromide stock solution.

SSR allelic composition for each genotype at every marker locus was determined by counting the frequency of major allele, number of genotype, number of alleles per locus, gene diversity, heterozygosity and polymorphic information content (PIC) value. Power marker version 3.25 (Liu and Muse, 2005) was used to perform those analyses. Dendrogram was constructed and cluster analysis was done with Un-weighted Pair Group Mean Algorithm (UPGMA) and similarity index developed by Nei et al. (1983) by MEGA 7.0 computer programme.

\section{RESULTS AND DISCUSSION}

\section{Morphological Screening}

Seedlings grew well without showing any abnormal conditions before commencing 
the salt stress. One week after the salt stress, varieties differently responded for salt stress. Pokkali IRRI accession, Pokkali local accession 5557 and IR42 varieties did not show stress symptoms. However, during the last few days of the stress period, salinity susceptibility symptoms such as drying and rolling of mature leaves were gradually developed in both Pokkali accessions. However, majority of the plants of Pokkali variety grew well without showing salt stress symptoms. Based on the mean separation score, both Pokkali accessions were significantly different from other varieties at the end of the stress period (Table 2). Average tolerance score of 3 was given for those two varieties. Both IRRI and local Pokkali accessions were categorized under the salinity tolerant category (T) based on the modified standard evaluating score system for salinity screening at the seedling stage developed by Gregorio et al. (1997b). The same local Pokkali accession (accession no. 5557) and Pokkali IRRI accession were categorized under tolerant (T) category after screening in $12 \mathrm{dSm}^{-1}$ stress solution for 14 days by Senanayake $e t$ al. (2017a and 2017b). However, Mohammadi-Nejadi et al. (2010) reported that the Pokkali IRRI accession showed highly tolerant (evaluating score 1) response reference to the same scoring system after following the same screening procedure after 14 days of stress period. However, based on this study, the Pokkali IRRI accession and Pokkali local accession (Bathalagoda accession no. 5557) were tolerant to salinity stress at the seedling stage and there was no significant difference in the tolerance level between the two varieties. Hence, those varieties can be used as donor parents for future salinity tolerance improvement programmes.

After one week of salinity stress, the varieties $\mathrm{Bg} 369, \mathrm{Bg} 359, \mathrm{IR} 42$ and IR46 began to gradually develop the salt stress symptoms. When it was 14 days of salinity stress, the symptoms could be well recognized. The symptoms based average tolerance score 5 was given for those varieties and it was significantly different form the Pokkali accessions. Bg369 symptoms were significantly different from other varieties, which scored a value of 5 and categorized under moderately tolerant category (Table 2). However, Senanayaka et al. (2017b) reported that the variety Bg369 was categorized under the salinity tolerant category at seedling stage. Therefore, the popular local variety Bg369 will be useful for cultivation in moderately saline regions. However, the salinity tolerance response of these varieties both at the vegetative and reproductive stages should be evaluated to arrive at a more precise conclusion.

Most part of the leaves of the $\mathrm{Bg} 357, \mathrm{Bg} 310$, Bg94/1, IR36, Bg380, At303 and At362 varieties were dried and seedling growth was severely retarded with the salinity stress at the end of 12 days. The tolerance score of these varieties was significantly different from moderately tolerant varieties. Average evaluating score of 7 was given for these varieties based on the symptoms and categorized under the salinity susceptible (S) category. The varieties $\mathrm{Bg} 250, \mathrm{Bg} 300$, Bg360, Bg358 and Bg370 almost withered and dried during seedling stage itself and no vegetative growth could be observed. The tolerance score of these varieties was significantly different from susceptible varieties. Average evaluating score of 9 was given for those varieties and were categorized under highly susceptible (HS) group. None of the varieties in the control experiment show any salt stress symptom and hence their salinity tolerance score was 1. Salinity affects all growth stages of the rice plant in varying degrees from germination to maturation. The rice plant is especially very sensitive to salinity during the early seedling and late reproductive stages (Lafitte et al., 2004). Therefore, the result of the morphological screening will be very useful for selecting the suitable varieties for the saline soils in Sri Lanka. Therefore, a prospective study to test the varietal response for salinity stress at the vegetative and reproductive stages would be helpful for further validation of the results. The final response of the 18 rice varieties for the salt stress after 14 days is shown in table 2 . 
Table 2: Summary of the phenotypic screening of the 18 rice genotypes for salt stress

\begin{tabular}{|c|c|c|c|c|}
\hline $\begin{array}{l}\text { Entry } \\
\text { no }\end{array}$ & Variety & Pedigree & $\begin{array}{l}\text { Evaluating } \\
\text { Score }\end{array}$ & $\begin{array}{l}\text { Reactions } \\
\text { to salinity }\end{array}$ \\
\hline 1 & Pokkali (IRRI)a & Not reported & 3 & $\mathrm{~T}$ \\
\hline 2 & Pokkali (5557)a & Traditional & 3 & $\mathrm{~T}$ \\
\hline 3 & $\mathrm{Bg} 369^{\mathrm{b}}$ & Bg94-2/ Nonabokra & 5 & MT \\
\hline 4 & $\mathrm{Bg} 359^{\mathrm{c}}$ & Bg88-5089/Bg 379-2 & 5 & MT \\
\hline 5 & IR46c & $\begin{array}{l}\text { IR1416-131-5/IR1364-37-3-1 } \\
\text { IR1366-120-3-1/IR1539-111 }\end{array}$ & 5 & MT \\
\hline 6 & IR42c & IR1561-228-1-2/IR1737 CR94-13 & 5 & MT \\
\hline 7 & $\mathrm{Bg} 380^{\mathrm{d}}$ & Bg90-2*/Ob677 & 7 & $\mathrm{~S}$ \\
\hline 8 & Bg357e & $\begin{array}{c}\text { BG797/BG300//85-1580/SenerangM- } \\
17\end{array}$ & 7 & S \\
\hline 9 & At303e & At66-2/Bg $276-5$ & 7 & $S$ \\
\hline 10 & $\mathrm{Bg} 310^{\mathrm{f}}$ & Bg 300/ Pokkali & 7 & S \\
\hline 11 & $\mathrm{Bg} 94 / 1^{\mathrm{h}}$ & IR262/Ld66 & 7 & S \\
\hline 12 & IR36h & Not reported & 7 & S \\
\hline 13 & At362g & At85-2/Bg380 & 7 & $\mathrm{~S}$ \\
\hline 14 & $\operatorname{Bg} 358^{\mathrm{i}}$ & Bg12-1/Bg1492 & 9 & HS \\
\hline \multirow{2}{*}{$\begin{array}{l}15 \\
16\end{array}$} & $\operatorname{Bg} 360^{\mathrm{i}}$ & 84-3346/IR36//Senarang & 9 & HS \\
\hline & $\mathrm{Bg} 370^{\mathrm{j}}$ & $\begin{array}{c}\text { IR555178/9-3R//IR65515-47-2- } \\
\text { 1/IR6551-47-2-1-91 }\end{array}$ & 9 & HS \\
\hline 17 & $\mathrm{Bg} 300^{\mathrm{k}}$ & Bg367-7//IR841/Bg276-5 & 9 & HS \\
\hline 18 & $\mathrm{Bg} 250^{\mathrm{k}}$ & Selection from farmer field & 9 & HS \\
\hline
\end{tabular}

Note: the mean followed by the same letter are not significantly different at $\mathrm{p}=0.05$

T-Tolerance, MT-Moderatly Tolerance, S-Susceptible, HS-highly Susceptible

\section{Molecular marker analysis}

The six markers were spanning for a $3.0 \mathrm{Mbp}$ length in the Saltol region of the chromosome one (Thomson et al., 2010). The SSR markers were based on the allele diversity which ranged from one hexa-allelic marker RM10843, one penta-allelic marker RM3412, one quard-allelic marker RM10852 and three bi-allelic markers RM8094, RM140 and RM10748. The RM10843 marker will be useful to perform a molecular diversity analysis between different Pokkali accessions in Sri Lanka, because Pokkali alleles were slightly distinguishable from other alleles of the different genotypes. Nineteen separate alleles were identified for six SSR markers with 3.5 average alleles per marker. Highest number of genotype number was six and it was given by RM 10843 markers. Mohommad-nejad et al. (2010) and Chowdhury et al. (2016) reported that RM8094 marker showed highest PIC value and highest number of marker alleles. The present study did not agree with those studies where RM8094 showed only two alleles for eighteen genotypes with low PIC value. Chowdhury et al. (2016) also reported that RM 10843 and RM3412 showed only three marker alleles among 54 rice genotypes in $6 \%$ poly acrylamide gel electrophoresis. In the present study same markers have given a 
high number of alleles even in 3\% agarose gel electrophoresis.

The polymorphic information content (PIC value) in the present study varied from 0.1780 to 0.7659 with an average 0.4650 . Based on the PIC value three markers, i.e. RM3412, RM10843 and RM 10852, were considered as highly informative because the PIC value was greater than 0.5. The highest PIC value was reported by RM10843 SSR marker as 0.7659. RM8094 SSR maker showed a PIC value of 0.3711 and it was considered as an informative marker because PIC ranges were 0.25-0.5. The markers RM140 and RM 10748 were considered as less informative because they showed a PIC value less than 0.25 (Table 3).

The marker alleles of RM10852 (Figure 1) was positively associated with the salinity tolerance genotypes. The marker alleles of the Pokkali IRRI accession and local accession were unique and discriminated salt tolerant and susceptible genotypes. The
RM10852 markers fairly discriminated the salinity tolerance genotypes even in 3\% Agarose gel. It is easy and less laborious compared with the polyacrylamide gel electrophoresis. Hence, this marker would be an effective tool for marker-assisted back-crossing. Huyen et al. (2013) reported RM10852 marker could discriminate the salinity tolerance and susceptible genotypes in $6 \%$ polyacrylamide gel electrophoresis. Therefore, further validation with polyacrylamide gel electrophoresis will be helpful to re-confirm the results of the present study. Furthermore, Pokkali marker allele RM10852 will be useful to select the back-crossed population, if the same Pokkali accessions is used as donor parents in marker assisted back-crossed programmes. The Pokkali allele of the RM10843 marker showed some separation from other alleles except for a few exceptions. However, polyacrylamide gel electrophoresis is needed to confirm whether it is clearly discriminate two salinity tolerance genotypes form others (Figure 2).

Table 3: Summary of the molecular marker analysis

\begin{tabular}{lccccc}
\hline Marker & $\begin{array}{c}\text { Major } \\
\text { Allele } \\
\text { Frequency }\end{array}$ & $\begin{array}{c}\text { No of } \\
\text { genotypes }\end{array}$ & $\begin{array}{c}\text { Allele } \\
\text { No }\end{array}$ & $\begin{array}{c}\text { Gene } \\
\text { Diversity }\end{array}$ & $\begin{array}{c}\text { Polymorphic } \\
\text { Information } \\
\text { Content (PIC) }\end{array}$ \\
\hline RM3412 & 0.2222 & 5.0 & 5.0 & 0.7963 & 0.7637 \\
RM10748 & 0.8889 & 2.0 & 2.0 & 0.1975 & 0.1780 \\
RM10843 & 0.2778 & 6.0 & 6.0 & 0.7963 & 0.7659 \\
RM140 & 0.8889 & 2.0 & 2.0 & 0.1975 & 0.1780 \\
RM10852 & 0.6111 & 4.0 & 4.0 & 0.5741 & 0.5332 \\
RM8094 & 0.5625 & 2.0 & 2.0 & 0.4922 & 0.3711 \\
Mean & 0.5752 & 3.5 & 3.5 & 0.5090 & 0.4650 \\
\hline
\end{tabular}


RM 8094 is one of the most tightly linked markers in Saltol QTL with highest LOD peak value and the maximum alleles were found for the RM8094 marker (Thomson et al., 2010; Islam et al., 2011). The previous studies conducted by Mohammad-Nejad et al. (2010), Thompson et al. (2010) and Babu et al. (2014) used RM8094 and RM3412 to test the discriminating ability of salinity tolerance and susceptible genotype. In those studies, maximum alleles were found for the RM8094 marker. Rice genotypes having Pokkali allele for RM8094 marker were strongly associated with tolerant or highly tolerant phenotypes during the morphological screening. However, in this study, this positive association was not identified for the RM8094 marker.

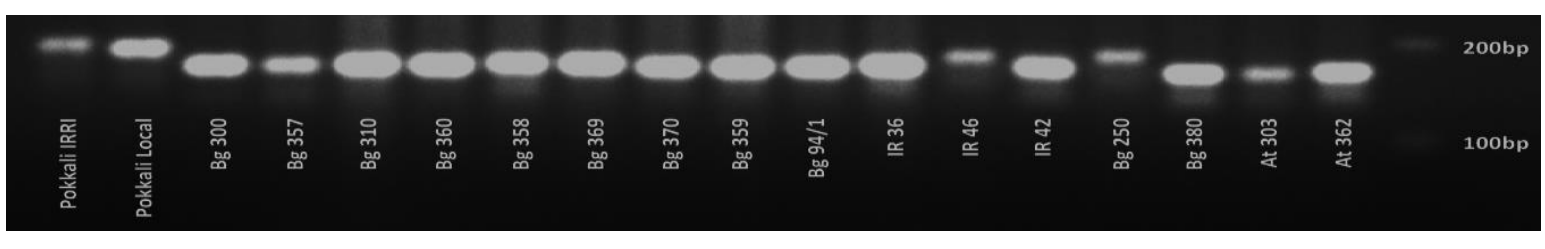

Figure 1: Amplified RM10852 marker alleles of 18 rice genotypes on 3\% Agarose Gel

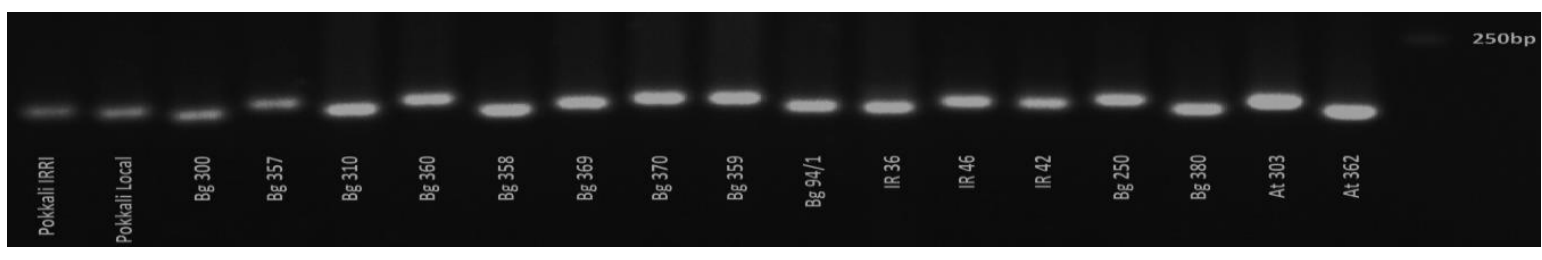

Figure 2: Amplified RM10843 marker alleles of 18 rice genotypes on 3\% Agarose Gel

\section{Cluster analysis}

According to the similarity matrix introduced by Nei et al. (1983), lowest genetic distance (0.333) was reported between Pokkali IRRI and Pokkali local accession which reflected the genetic closedness between the Pokkali local and Pokkali IRRI varieties. The UPGMA analysis defined all 18 rice genotypes into two clusters (Figure 3). Cluster one consisted of the salinity tolerance genotypes which consisted of only the Pokkali IRRI accession and Pokkali local accession. These two varieties were clearly divergent from the moderately tolerant, susceptible and highly susceptible varieties during the phenotypic screening too. Therefore, phenotypic screening results were further confirmed by salinity tolerance accessions by the cluster analysis. The results also showed that the salinity tolerance of the Pokkali accessions share a common allele for the markers.
Therefore, screening of all local Pokkali accessions and genotyping with more tightly linked SSR markers to Saltol region will be useful to further explain the relationship between Pokkali allele of the marker and salinity tolerance response during the seedling stage.

The second cluster was divided into two subclusters (Figure 3). Moderately salinity tolerant and susceptible varieties were distributed in these two clusters and it was difficult to explain the common relationship of the varieties in cluster 02 and sub-cluster of the cluster 02 . The moderately tolerant varieties Bg359 and Bg369 were clustered in sub cluster 02. Therefore, the salinity tolerance relationship among these varieties at the seedling stage is difficult to explain by these markers, because the salinity tolerance mechanism of seedling stage regulation is done by many other QTLs in addition to Saltol QTLs. Gregorio (1997a) 
reported that the Saltol QTL governed the $\mathrm{Na}^{+} / \mathrm{K}^{+}$uptake by 64.3 to $80.2 \%$, and Thomson et al. (2010) reported the Saltol is responsible for $60 \%$ total phenotypic variations of the seedling stage salinity tolerance in rice. Many QTLs which are responsible for seedling stage salinity tolerance in rice were mapped in the chromosome 2, 3, 4, 6, 9 and 12 of the rice genome (Thomson et al., 2010) (Figure 3).

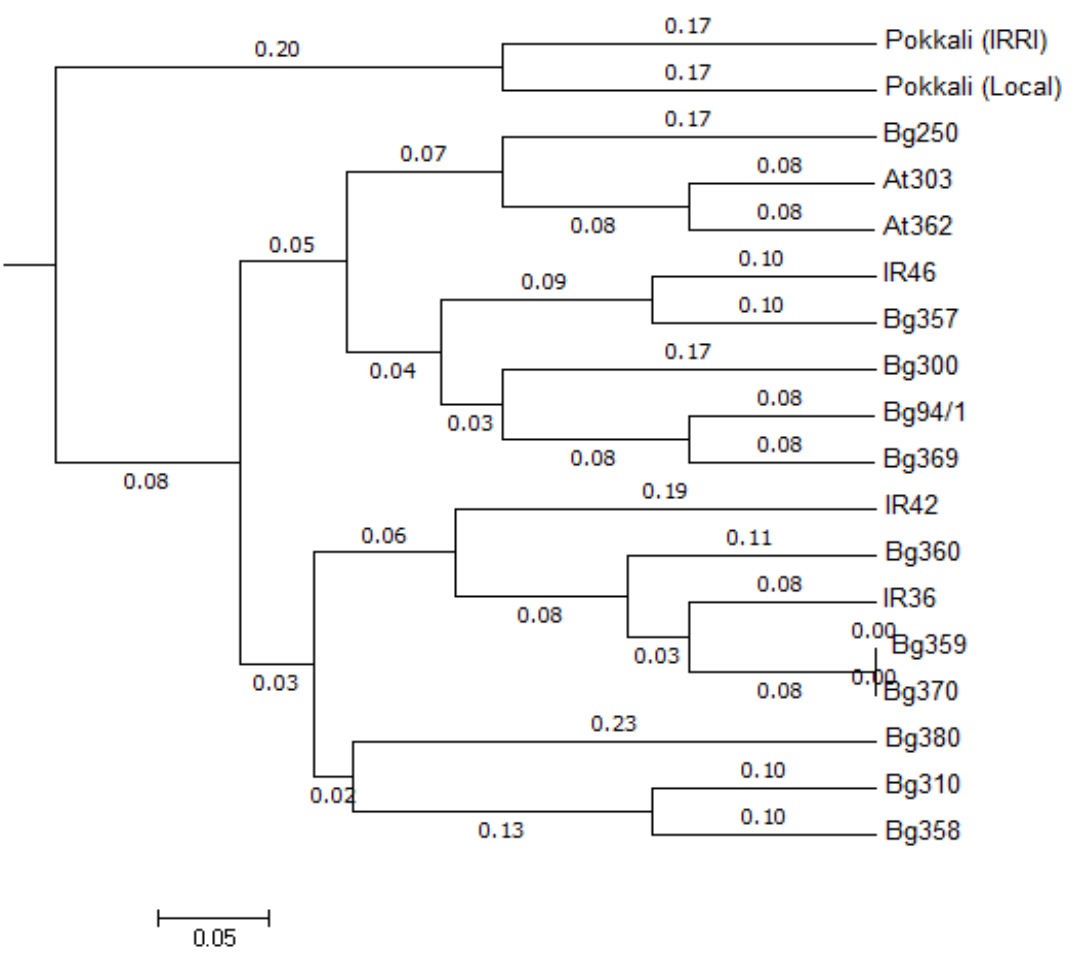

Figure 3: Dendrogram of the 18 rice genotypes based on six polymorphic SSR markers in the Saltol region according to the un-weighted pair group mean algorithm (UPGMA) with Nei's similarity index.

\section{CONCLUSIONS}

Pokkali IRRI accession and Pokkali local accession (RRDI Batalagoda accession 5557) were tolerant to salinity stress at the seedling stage. Hence, those varieties will be useful as donor parents for future salinity tolerance improvement programmes. The popular local rice varieties Bg359 and Bg369 were moderately tolerant for salinity stress at the seedling stage. Therefore, these varieties will be useful for the soils which are moderately affected by the salinity.

The microsatellite marker (SSR) RM10852 was positively associated with salinity tolerance rice genotypes in the $3 \%$ agarose gel electrophoresis. Therefore, this marker will be useful for Marker Assisted Selection
(MAS) in rice breeding programmes and detecting the salinity tolerant Pokkali allele in the back-crossed population derived from the same Pokkali accession as donor parent. However, further validation will be needed to test the discriminating ability of salinity tolerant and susceptible genotypes by RM 10843 marker with polyacrylamide gel electrophoresis.

\section{ACKNOWLEDGEMENTS}

The authors wish to acknowledge Dr. A.P. Benthota, former Director, Rice Research and Development Institute, Batalagoda, Sri Lanka, Dr. W.L.G Samarasinghe, Deputy Director of Plant Genetic Resource Center, Gannoruwa, Peradeniya, Sri Lanka, Dr. D.R. Gimhani, Lecturer, Department of 
Biotechnology, Faculty of Plantation Management, Wayamba University of Sri Lanka, Mrs. D.S. Kakulandara, Research Officer, Division of Biotechnology, RRDI Batalagoda, Sri Lanka and Mr. Susan Gunasena, Research Assistant, Division of Biotechnology, RRDI, Batalagoda, Sri Lanka, for their contributions.

\section{REFERENCES}

Babu, N.N., Vinod, K.K., Gopala Krishnan, S., Bhownick, K., Vanaja, T., Krishnamurthy, S.L., Nagarajan, M., Sing, N.K., Prabhu, K.V. and Sing, A.K. (2014). Marker-based Haplotype Diversity of Saltol QTL in Relation to Seedling Stage Salinity Tolerance in Selected Rice Genotypes of Rice. Indian Journal of Genetics. 74(1), 16-25.

Bonila, P., Deorak, j., Mackill, D., Deal, K., and Gregorio, G. (2002). RFLF and SSL mapping of salinity torelarnce genes in chromosome 1 of rice (Oryza sativa L.) using recombinant inbred lines. Philippine Journal of Agricultural Science. 85, 68-76.

Chowdhury, A.D., Haritha, G., Sunitha, T., Krishnamurthy, S.L., Diviya, B., Padmavatie, G., Ram, T. and Sarla, N. (2016). Haplotyping of rice genotypes using simple sequence repeat markers associated with salt tolerance. Journal of Rice Science. 23(6), 317-325.

De-Costa, W.A.J.M., Wijeratne, M.A.D., and Zahra, A.R.F. (2012). Determination of the Appropriate Level of Salinity for the Screening of Hydroponically Grown Rice for Salt Tolerance, Journal of National Science Foundation Sri Lanka. 40(2), 123-136.

Gregorio, G.B. (1997a). Tagging Salinity Tolerance Genes in Rice Using Amplified Fragment Length Polymorphism (AFLP). $\mathrm{PhD}$ thesis, University of, Los Banos, Philippines.

Gregorio, G.B., Senadhira, D. and Mendoza, R.D. (1997b). Screening rice for salinity tolerance, IRRI Discussion Paper Series no. 22. International Rice Research Institute Los Banos, Laguna, Philippines.
Huyen, L.T.N., Cuc, L.M., Ham, L.H. and Khanh, T.D. (2013). Introgression the Saltol QTL into Q5BD the Elite Variety of Vietnam Using Marker-Assisted Selection (MAS). American Journal of BioScience. 1, 80-84.

Islam, M.R., Salam, M.A., Hassan, L., Collard, B.C.Y., Singh, R.K. and Gregorio, G.B. (2011). QTL Mapping for Salinity Tolerance at Seedling Stage in Rice. Emirates Journal of Food \& Agriculture. 23, 137-146.

Lafitte, H.R., Ismail, A. and Bennett, J. (2004). Abiotic Stress Tolerance in Rice of Asia: Progress and the Future. Fischer, T., Turner, N. Angus. J. Mclntyer, L. Robertson. M and Borrell. A. (Ed). In: New Directions for a Diverse Planet: Proceedings of the $4^{\text {th }}$ International Crop Science Congress. Brisbane, Australia.

Li J.Y., Wang, J., Zeigler, R.S. (2014).The 3,000 Rice Genomes Project:New Opportunities and Challenges for Future Rice Research. Gigascience. 3- 8

Liu, K. and Muse, S.V. (2005). Power Marker, an integrated analysis environment for genetic marker analysis. Bioinformatics, 21, 2128-2129.

Mohammadi-Nejad, G., Singh, R.K., Arzani, A., Rezaie, A.M., Sabouri, H. and Gregorio, G.B. (2010). Evaluation of Salinity Tolerance in Rice Genotypes. International Journal in Plant Production.4, 199-208.

Nei, M., Ajima, F. and Tateno, Y. (1983). Accuracy of an Estimated Phylogenetic Tree from Molecular Data. Journal of Molecular Evaluation 19, 153-170.

Platten, J.D., Cotsaftis, O., Berthomieu, P., Bohnert, H. and Davenport, R.J. (2006). Nomenclature for HKT Transporters, Key Determinants of Plant Salinity Tolerance. Trends Plant Science, 11,372 - 384.

Rajadurai, S. (2003). Rainfed rice cultivation in Jaffna district. Smart prints, Jaffna, pp 1-5.

Ren, Z.H., Gao, J.P., Li, L.G., Cai, X.L., Huang. W. and Chao, D.Y. (2005). A rice Quantitative 
Trait Locus for Salt Tolerance Encodes a Sodium Transporter. Nature Genetics. 37, 1141-1146.

Senanayake, R.M.N.H., Udawela, U.A.K.S., Sandaruwan, L.M.U., Wijerathana, D.G.K.P., Amarasingha, A.A.P.G., Wijepala, W.G., Dharmasiri, H.G.S.B. and Gunasena, G.S.D. (2017a). Identification of Salinity tolerant accessions of traditional rice variety 'Pokkali', Annals of Sri Lanka, Department of Agriculture, 19 (2):1-15.

Senanayake, R.M.N.H., Herath, H.M.V.G., Wickramesinghe, I.P., Udawela, U.A.K.S. and Sirisena D.N. (2017b). Phenotypic Screening of Rice Varieties for Tolerant to Salt Stress at Seed Germination, Seedling and Maturity Stages. Tropical Agricultural Research Vol. 29 (1): $90-100$.

Sirisena, D.N. and Herath, H.M.A. (2009). Productivity Enhancement in Saline Paddy Fields in Angithankulam Yaya in Sri Lanka. In: Proceedings of the $9^{\text {th }}$ International Conference of East and Southeast Asia Federation of Soil Science Societies,. Seoul, Korea 507-508.
Soda, N., Kushwaha, H.R., Sonil, P., SinglaPareek, S.L. and Pareek, A. (2013). Asuit of new genes defining salinity stress tolerance in seedlings of constrasting rice genotypes. Functional and integrative genomics, 13, 351-365.

Thompson, M,J., Ocammpo, M., Egdane, L., Rahman, M.A., Sajis, A.G., Aorda, L., Tumimbang-Raiz, E., Blumwald, E., Sera,j A.I., Sing, R.K., Gregorio, G.B. and Smail, A.M. (2010). Characterizing the Saltol Quantitative Trait Locus for Salinity Tolerance in Rice. Rice, 3(2), 148-160.

Vinod, K.K. Krishnan, G.S. Babu, N.N. Nagarajan. M. and Singh, A.K. (2013). "Improving Salt Tolerance in Rice: looking beyond the conventional, pp 219-260. In: Ahmad, P, Azoos, M.M and Prasad. M.N.V.(Ed.) Salt Stress in Plants Signalling, Omics and Adaptations. Springer, New York.

Zeng, L. and Shannon, M.C. (2000). Salinity Effects on the Seedling Growth and Yield Components of Rice. Crop Science, 40, 9961003. 